Association for Information Systems

AIS Electronic Library (AISeL)

Wirtschaftsinformatik 2021 Proceedings

Track 2: General Track - Innovative, emerging and interdisciplinary topics

\title{
Data Strategy Development: A Taxonomy for Data Strategy Tools and Methodologies in the Economy
}

Inan Gür

Fraunhofer ISST

Markus Spiekermann

Fraunhofer ISST

Michael Arbter

Fraunhofer ISST

Boris Otto

Technische Universität Dortmund; Fraunhofer ISST

Follow this and additional works at: https://aisel.aisnet.org/wi2021

Gür, Inan; Spiekermann, Markus; Arbter, Michael; and Otto, Boris, "Data Strategy Development: A Taxonomy for Data Strategy Tools and Methodologies in the Economy" (2021). Wirtschaftsinformatik 2021 Proceedings. 1.

https://aisel.aisnet.org/wi2021/YGeneralTrack/Track02/1

This material is brought to you by the Wirtschaftsinformatik at AIS Electronic Library (AISeL). It has been accepted for inclusion in Wirtschaftsinformatik 2021 Proceedings by an authorized administrator of AIS Electronic Library (AISeL). For more information, please contact elibrary@aisnet.org. 


\title{
Data Strategy Development: A Taxonomy for Data Strategy Tools and Methodologies in the Economy
}

\author{
Inan Gür ${ }^{1}$, Markus Spiekermann ${ }^{1}$, Michael Arbter ${ }^{1}$, and Boris Otto ${ }^{1,2}$ \\ 1 Fraunhofer Institute for Software and Systems Engineering, Dortmund, Germany \\ \{Inan.Guer,Markus.Spiekermann,Michael.Arbter,Boris.Otto\}@isst.fraunhofer.de \\ 2 TU Dortmund, Chair for Industrial Information Management, Dortmund, Germany \\ \{Boris.Otto\}@tu-dortmund.de
}

\begin{abstract}
Data are a key driver of the digital era. They shift the strategic landscape of organizations and change how companies approach their business. Nevertheless, existing approaches on data strategies vary vastly and little common ground is visible. Therefore, we develop a comprehensive taxonomy for data strategy tools and methodologies in order to identify characteristics and relevant properties of data strategy. We derived the taxonomy inductively by analyzing existing data strategy tools and methodologies offered in the current economy and deductively by conducting a structured literature review on the existing body of knowledge in the scientific literature. It serves as a scientific instrument to profoundly assess and create data strategies and work towards a consensus in the respective research field.
\end{abstract}

Keywords: Data Strategy, Digital Strategy, IT-Strategy, Taxonomy

\section{Introduction}

In the digital era, in which organizations need to improve their response to ever changing and faster markets [1], companies need a strategy to react to the forces and influences of the surrounding environment. To respond to internal and external dynamics as well as to reduce uncertainty, companies form strategies and create a shared understanding of goals within the entire organization [2]. [3] claimed that the field of strategic management needed more than one definition for the concept of strategy, since the term is being used in various ways. In that regard, he gave five definitions: strategy as plan - a consciously intended course of action and guideline to deal with a situation -, strategy as ploy - a specific maneuver intended to outwit an opponent or competitor -, strategy as a pattern - a stream of actions -, strategy as position - means of locating an organization in an environment - and strategy as perspective - an ingrained way of perceiving the world by the pursuer [3]. In any manner, strategy, while being complex, has to provide guidance [4] on how to achieve competitive advantage [5]. It is the essence of what a business does different or better than competitors in order to gain sustainable advantage and achieve its declared objectives [6]. 
For crucial competitive innovations and advantages, nowadays data lay the foundation and are the driver of the digital economy [7]. With the advances of data generation and collection technologies, vast amounts of data are available and accessible [8,9]. Data enable organizations to make rational and resourceful use of information and therefore empower them to better decision-making processes and better realization of their strategic objectives [10]. Hence, using data strategically and creating a unique organization-wide data strategy is indispensable. Nevertheless, surveys e.g. the on from [11], which was conducted within 189 companies and published in the Harvard Business Review in 2018, indicate, that still today many companies struggle in proper implementation and execution of profound and welldefined data strategies, even though data itself or the amount of data sources do not pose a problem [12]. The benefits of strategic data usage are widely known [13].

In that regard, more and more organizations publish their own understanding of data strategy and offer data strategy methodologies or tools e.g. [14-16]. These methodologies and tools serve as an endeavor to define a data strategy approach and develop a distinctive data strategy perspective. Similar methodologies on data strategy can be found in academic literature as elaborated by [17]. Nevertheless, to the best of our knowledge, there is little scientific work towards a consensus for data strategy in the current economy. Practitioners would benefit from better elaboration, since they would profit from a comprehensively acknowledged understanding of data strategy and its properties to develop an appropriate data strategy on their own. Researchers would benefit from a structured analysis of data strategies both in the economy and in academic environments. The goal of this study is to create a unifying perception on data strategy by consolidating scientific and economic knowledge on data strategy. Therefore, our research question reads as follows:

Research Question: What are the characteristics and relevant properties of data strategy tools and methodologies offered in the current economy and academic literature?

To answer this research question, we follow the approach for taxonomy development by Nickerson [18]. We chose the artifact of a taxonomy, since taxonomies reveal valuable insights and analyze, structure and conceptualize complex entities [19]. We decided on this development procedure, since Nickerson's approach allows a deductive iteration on relevant objects from the targeted area as well as an inductive iteration on the existing body of knowledge in academic literature for data strategy.

On that regard, our work is structured as follows: After the introduction we set the theoretical foundation by defining data strategy research in the field of Information Systems (IS) and circumventing the concepts from other terms. In the following, we elaborate the given research design by outlining, presenting and discussing our course of action and procedural method concerning the taxonomy process and structured literature review. In chapter four we present our final taxonomy and elaborate the results. Finally, in the last sections we discuss our implications, limitations of the research and future research. 


\section{Theoretical Foundation}

Derived from business strategy there are variations, which differ in the level of abstraction while addressing strategical considerations in specific business areas or organizational functions.

In order to comply with scientific rigor it is important to get an overview of the strategical perspective that is related to the data strategy, which we discuss in the paper. During our Structured Literature Review (SLR), which is described in the following section, we identified digital strategy as well as IT-strategy as related derivations. By comparing the three, one can better understand the addressed dimensions they have in common and the ones that characterize the specific approaches.

\subsection{Data Strategy}

Data are creating a new generation of decision support data management [20] and disruptively changes the way business can be strategically approached [21]. That applies not only on a functional level but also on a corporate level to a point that it shifts the strategic landscape and how companies approach and evaluate their business models [9]. Generating value from data has reached a broad notion, that a wellorganized data management can only be achieved with a coherent strategy for organizing, governing, analyzing and deploying the organization's data assets [22]. In that regard, developing a data strategy on how to extract value from data is crucial for today's organizations [12]. A data strategy can be defined as a "blueprint that requires the establishment of goals, identification of data sources and the use of analysis" [23] in order to "find the right questions [...] from strategic thinking in collaboration with technological savviness" [24] to create "additional value for internal and external stakeholders" [2]. The data strategy sets a clear direction for data value generation, ensures that all stakeholders work towards the same objective and is linked to the business unit level strategy on a functional level [2]. Several authors pick up on Davenports conception of data strategy as the most important step of data initiatives [25] as it describes the objectives, scope and advantages on a fundamental basis for data value generation [6 p.3].

\subsection{Digital Strategy}

Digital Strategy can be seen as the most extensive focus, since it represents the first level of the fusion of IT and business strategy by tactfully incorporating digital technologies in the business strategy $[21,26]$. The definition of digital business strategy is given as an "...organizational strategy formulated and executed by leveraging digital resources to create differential value" [27] and assesses the changes of how business is conducted due to digital technologies [28, 29]. Out of new capabilities enabled by these technologies, companies can create new value propositions by combining them with already existing capabilities. This encompass strategic, technological, human capital, and organizational culture considerations within the company and defining a strategy for its digital transformation [30]. This does not necessarily replace any former 
strategies, but most likely will need to be aligned with them [26]. This could be either done by common targets in customer-centricity or based on companies' digitized solutions. While the first aims at higher engagement and building trust and creating loyalty, the second focuses on the transformation of the business model towards digitized products and value-added services to create recurring revenue [31,32]. Both approaches have in common, that the most important aspect are the business capabilities enabled by these strategies to build efficiency and technical reliability, agility and innovation [29]. A digital strategy is inherently multi-functional [27]. Alignment requires the simultaneous development and reinvention of business resources, especially IT and data resources, across multiple organization processes [33].

\section{$2.3 \quad$ IT-Strategy}

The crucial roles of IT and IT strategy are to support and enable the business [27, 34 , 35]. An IT strategy is described as the "...planning and transformation of strategic IT goals into IT governance structures, IT processes, applications and infrastructure by adjusting them to the business" [35]. The implementation leads to improved control of investments, deployments and usage of IT, which leads to higher efficiency, productivity and revenues in the business [36, 37]. Due to the importance of IT for the business, alignment of IT and business is an essential component of IT strategies. Consequently, the boundaries between the IT strategy as a functional strategy and the business strategy are becoming increasingly fuzzy, resulting in new strategy development streams (digital business strategy). Therefore, the development of the IT strategy can be an integrated part of the digital business strategy or can be derived from the business strategy [27, 35, 38]. Considering IT as a functional strategy, three substrategies are relevant in addition to the IT mission and vision: Information Systems (IS-Strategy), Information Management (IM-Strategy) and the Information and Communication Technology (ICT-Strategy). All three sub-strategies are related and influence each other. They define which requirements are mandatory (IS-Strategy), how the IT organization is aligned (IM-Strategy) and which infrastructure complies with the requirements (ICT-Strategy) [39, 40]. However, often times the successful instantiation of an IT strategy lacks detailed concepts for implementation and continuous alignment $[35,41]$.

\section{$3 \quad$ Research Design}

\subsection{Methodology by Nickerson}

For this research, we decided to follow the taxonomy development method by Nickerson et al. [18] as it is a frequently used method in IS research publications e.g. [42-45]. This method is consistent with the design science research guidelines of Hevner et al. [46] and consists of seven steps (see fig. 1). The first step is the identification of the meta-characteristic which derives from the purpose of the taxonomy and its expected use. Since this method is an iterative process, the second 
step is to define ending conditions which "determine when to terminate" [18]. This research follows the eight objective and five subjective ending conditions given out by Nickerson et al. [18]. The next step requires the selection of one of two approaches to identify the characteristics and dimensions of the taxonomy. The user of the method can either chose a conceptual-to-empirical approach, which follows a deductive procedure to derive characteristics and dimensions from the theory, or an empirical-toconceptual approach can be chosen, in which results are derived inductively from a particular set of objects. The method is executed for as long as ending conditions are not met, which would terminate the iterative design process.

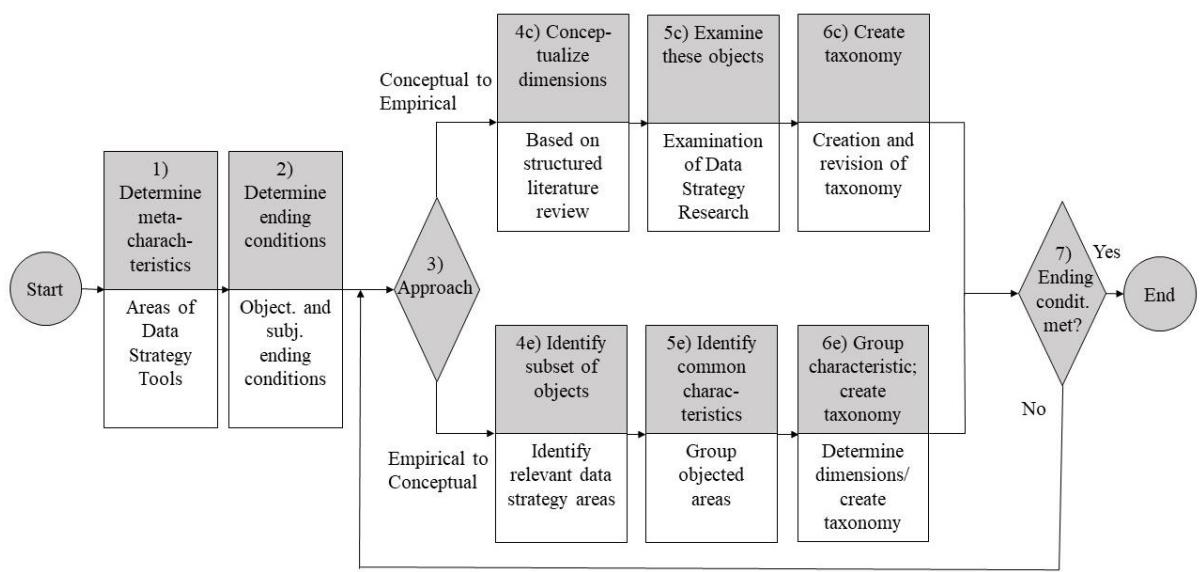

Figure 1 Taxonomy development method according to Nickerson et al. [18]

\subsection{Taxonomy development process}

Meta-characteristics: The meta-characteristic is "based on the purpose of the taxonomy" [18]. The purpose of the taxonomy is defined by the target group and intended future use. In regard to this, we set the meta-characteristic following the research question as "characteristics and areas of data strategy tools".

$\mathbf{1}^{\text {st }}$ Iteration (Empirical-to-Conceptual): For the first iteration we chose an empiricalto-conceptual inductive approach. In this context, we conducted an analysis of data strategy tools and methodologies in the economy following the descriptive review process in IS research elaborated by King [47] and Pare [48]. The descriptive review intents to reveal the body of empirical studies in a specific research area and therefore involves a systematic search of as many relevant objects in the investigated area as possible, while collecting, coding and analyzing the results concerning a certain interest from each study $[47,48]$. To ensure the rigor in the conducted systematic search, we followed the guidelines for literature reviews proposed by vom Brocke et al. [49].

The first step of the procedure was the search process involving the keywords, database, backward and forward search and the evaluation of sources [49]. To systematically identify relevant objects, we used the Google search engine to secure a heuristic search without domain or industry boundaries. We set the keywords to ("Data 
Strategy" AND (Tool OR Framework)) and stretched the search up to first 150 results. We scanned for data strategy methodologies published by organizations through whitepapers, insights and reports, because these publications offer further information and application indications on the respective tools. We only included publicly available results, which provided thorough information and were written in English. We conducted a backward and forward search to see if the organizations offered more recent objects or referred to other data strategy methodologies. Our search yielded 16 objects, from which 10 met the criteria. They cover a variety of different domains and are extracted from organizations ranging from 11 employees up to +10000 , including start-ups and established companies.

The next step of this iteration was the analysis of the research objects. We decided to conduct the investigation by three researchers individually and independently to prevent bias. The three researchers analyzed the methodologies and tools concerning relevant characteristics, targeted areas and functions. The results were discussed in a one day workshop, including the fourth researcher as a "devil's advocate" to ensure critical distance and a broad discussion to identify relevant dimensions and characteristics for the taxonomy.

$2^{\text {nd }}$ Iteration (Conceptual-to-Empirical): In order to meet the proposed ending conditions, we additionally performed a conceptual-to-empirical deductive iteration. Therefore, we conducted a SLR as a "systematic, explicit and reproducible method for identifying, evaluating and synthesizing the body of completed and recorded work by researchers, scientists and practitioners" [50]. In order to meet the quality requirements of appropriate research breadth, rigor, consistency, clarity and brevity [51], we followed the approach of Webster and Watson [52] and vom Brocke et al. [49, 53].

The scope of this research can be allocated in the scientific domain of Information Systems (IS). We selected the four literature databases, "Scopus", "Emerald Insight", "Aisel" and "IEEE Xplore", since these databases include relevant IS research journals and scientific conferences. We determined three search terms, namely "Data Strategy", "Digital Strategy" and "IT Strategy" to cover the research field and ensure the traceability, repeatability and transparency of the search. The search yielded 3613 results in total. After the first filter process, based on the title, 103 publications remained. A second filter process based on the abstract and content reduced the findings to 49. Thereafter, duplicates have been filtered and a forward and backward search has been conducted, after which the literature basis for the analysis resulted in 48 scientific publications (see table 1). These 48 publications were analyzed concerning key characteristics and crucial elements of data strategy development in organizations. 
Table 1 Structured literature review results

\begin{tabular}{|l|l|l|l|l|l|}
\hline \multicolumn{1}{l}{ Scopus } & \multicolumn{1}{l}{ Emeral } & \multicolumn{1}{l}{ Aisel } & \multicolumn{1}{l}{ IEEE } & \multicolumn{1}{l}{ Relevant } \\
\hline "Data Strategy" & 483 & 175 & 25 & 51 & 16 \\
\hline "Digital Strategy" & 481 & 394 & 64 & 37 & 9 \\
\hline "IT Strategy" & 789 & 387 & 571 & 156 & 24 \\
\hline & & & Duplicates filtered & -5 \\
\hline & & & F. and B. Search & 4 \\
\hline
\end{tabular}

Ending conditions: We used the eight objective and five subjective ending conditions elaborated by Nickerson to determine the ending of the iteration process. After the first iteration, seven of the 13 ending conditions were met. Since the results from the first iteration were not sufficient to fulfill every ending condition acceptably, we conducted the second conceptual-to-empirical approach in the form of a structured literature review. After the elaborated meeting to discuss the results, the identified dimensions and characteristics for the taxonomy indeed met the required conditions. These results and the final taxonomy will be presented and discussed in the next section.

\section{$4 \quad$ Results}

\subsection{Dimensions and Characteristics}

The resulting taxonomy consists of 9 dimensions $\left(D_{\mathrm{x}}\right)$ with 30 corresponding characteristics $\left(\mathrm{c}_{\mathrm{xy}}\right)$. To showcase the application of the taxonomy, we implemented the 10 objects that formed the basis for the empirical-to-conceptual iteration (see tab. 2). In the following, we explain our findings along the dimensions and characterizations.

The first two dimensions were derived by Etsiwah and Hilbig [17]. The dimension Purpose ( $\left.\mathbf{D}_{1}\right)$ "describes the objective of a data strategy within an organization" [17]. This dimension consists of three corresponding characteristics. The characteristic Product Development $\left(\mathrm{c}_{11}\right)$ is on hand when the data strategy is designed to create new products or innovate existing products. In this case the data strategy helps to identify use cases for data analytics and plans the implementation in product development [2]. Such a data strategy is especially crucial for the development and improvement of connected, digital or smart products [12]. The characteristic Business Dev. $\left(\mathrm{c}_{12}\right)$ describes the cases in which the data strategy generates changes on a business model level. Data enables disruptive innovations that change the way a business can be approached and business decisions can be made more strategically [21]. A data strategy shifts the strategic landscape and further promotes the evolution of existing business models [9]. The characteristic Strategy Development $\left(\mathrm{c}_{13}\right)$ is on hand when the strategy is set to design a strategy based and solemnly on data [17] separated from other business functions. 
The second dimension Level $\left(\mathbf{D}_{2}\right)$ "provides a link to traditional classifications of strategy in strategic management literature as it describes the scope of a given data strategy" [17 p.5]. It provides a co-evolutionary strategy alignment with other strategies within an organization [54]. The data strategy can be on a functional $\left(\mathrm{c}_{21}\right)$ level, aligned with e.g. product development or marketing. Furthermore, the data strategy can be on a business $\left(\mathrm{c}_{22}\right)$ level, linked to business units and deciding which on markets the business competes or the data strategy can be on a corporate $\left(\mathrm{c}_{23}\right)$ level, setting the objectives and direction of a company [2].

The third dimension Practice $\left(D_{3}\right)$ describes in which form the organizations offer their data strategy tool or methodologies. The analysis of the different objects showed, that the data strategy tools are generally set out as a method $\left(\mathrm{c}_{31}\right)$, defining certain steps to derive a data strategy, or as a model ( $\left.\mathrm{c}_{32}\right)$, giving logical and objective representations of empirical objects. Objects that could not be assigned to one of the two characteristics fall under the third characteristic general framework $\left(\mathrm{c}_{33}\right)$.

The fourth dimension Data Asset $\left(\mathrm{D}_{4}\right)$ describes on what data the data strategy methodology focusses. The iterative analysis yielded four predominant data types. The characteristic master data $\left(\mathrm{c}_{41}\right)$ is on hand when the data strategy focusses on the core data entities of an enterprise [55]. Customer data $\left(\mathrm{c}_{42}\right)$ involves data from and around stakeholders on a customer level, including retailers and end customers [56] and transactional data from business documents [57]. Process Data $\left(\mathrm{c}_{43}\right)$ describes all data from the value generation process like the operation of machines or processing units that provide valuable information about value generation processes [19]. Big data $\left(\mathrm{c}_{44}\right)$ is characterized by the key attributes of great variety, high velocity and high volume [10] measuring tens of terabytes demanding big data analytic methods [58].

The fifth dimension is Data Source $\left(D_{5}\right)$. It describes where the focused data of the data strategy originates and is acquired. This dimension can be divided into internal $\left(c_{51}\right)$ data sources and the combination of internal and external $\left(\mathrm{c}_{52}\right)$ data sources [45]. Internal data sources can be self-generated data from the organization's assets like machine sensor data [43]. External data can be obtained from outside the organization in various ways e.g. like free data or acquired data from providers like data marketplaces [44].

The sixth dimension shows to what extend the data strategy requires a Strategic Statement $\left(D_{6}\right)$. Strategy, thoroughly discussed in literature and commonly used in business, generally defines the purpose and objectives of an organization to reduce uncertainty provide direction for decisions [2]. This dimension is divided into the three characteristics, namely vision $\left(\mathrm{c}_{61}\right)$, mission $\left(\mathrm{c}_{62}\right)$ and objectives $\left(\mathrm{c}_{63}\right)$. The vision is the definition of the "end-state towards which the organization strives" [56], whereas the mission defines the primary activities to reach the vision [56]. Fundamental for strategy development is a clear set of objectives $[6,59]$.

The seventh dimension describes the Business IT Alignment $\left(D_{7}\right)$. This dimension defines the continuous fit between IT applications and infrastructure on one hand and business strategy and processes on the other [33, 39]. The alignment is a key process to maintain business value as it models business and IT together in a common organizational framework to define the future state [56]. It is a dynamic and continuous process that adjusts and synchronizes business and IT [40] and enables data initiatives 
[33]. The analysis yielded four characterizations that are most relevant within a data strategy initiative, namely the alignment of objectives $\left(\mathrm{c}_{71}\right)$, architecture $\left(\mathrm{c}_{72}\right)$, people $\left(\mathrm{c}_{73}\right)$ and communication $\left(\mathrm{c}_{74}\right)$ in terms of canals and processes.

Strategy Implementation $\left(D_{8}\right)$ is the eighth dimension as it is a primary success factor in strategy development [60], offering clear benefits when conducted successfully [24]. It is defined by three dominant characteristics, namely road map $\left(\mathrm{c}_{81}\right)$, roles $\left(\mathrm{c}_{82}\right)$ and resource allocation $\left(\mathrm{c}_{83}\right)$. The creation of a road map is a crucial task in the implementation of data strategy, as it describes the timeline for the implementation process including different use cases and required tasks of the involved stakeholders [2]. Furthermore, the implementation sets out specific roles like chief data officers or data-management functions [22] to effectively execute the data strategy. The resource allocation defines the resources required to implement and achieve the data strategy and considers whether the resources are allocated internally or externally [61].

The ninth dimension concretizes the Service and Support $\left(D_{9}\right)$ the applicant of the data strategy tool receives. As stated in the beginning of this paper, there are several sustainable advantages of conducting a data strategy [10]. The analyzed objects focus on four specific benefits and offer service and support in that regard: use case derivation $\left(\mathrm{c}_{91}\right)$, data management optimization $\left(\mathrm{c}_{92}\right)$, analytics improvement $\left(\mathrm{c}_{93}\right)$ and strategic management improvement $\left(\mathrm{c}_{94}\right)$. The first characterization focusses on data strategy development, which supports the identification of use cases for e.g. data analytics or data strategy implementation [2]. The second characterization is on hand, when the respective data strategy tool aims to develop a data strategy primary to enable superior data management capabilities [22]. The third characterization focusses on obstacles and barriers in organization [13], which constrain the data analytics capabilities, since these challenges are often of organizational and strategic nature [60]. The fourth characterization is on hand for data strategy tools focusing on improving the general strategic management of the organization by implementing a data strategy to e.g. timing of and general decision-making [21].

\subsection{Application of the Data Strategy Tool Taxonomy}

Table 2 shows the final taxonomy including the application on the ten data strategy tools and methodologies yielded from the first iteration. The classification of empirical objects verifies the usefulness of our taxonomy using the ten examples [18]. As explained in our empirical-to-conceptional iteration, the tools originate from organizations out of a variety of different branches, industries and sizes, showcasing the generality and applicability of our taxonomy. 
Table 2 Taxonomy of data strategy tools and methodologies

\begin{tabular}{|c|c|c|c|c|c|c|c|c|c|c|c|}
\hline & & & & Data & rateg & Tool & ind $\mathrm{M}$ & hodo & gies & & \\
\hline Dimensions & $\begin{array}{l}\text { Characteri } \\
\text { stics }\end{array}$ & $\begin{array}{l}\text { Booz } \\
\text { Allen } \\
\text { H. [62] }\end{array}$ & $\begin{array}{l}\mathrm{CDQ} \\
{[63]}\end{array}$ & $\begin{array}{l}\text { Measur } \\
\text { elab } \\
{[64]}\end{array}$ & $\begin{array}{l}\mathrm{BC} \\
\mathrm{G} \\
{[65]}\end{array}$ & $\begin{array}{l}\text { Kell } \\
\text { er } \\
{[66]}\end{array}$ & $\begin{array}{l}\text { Glob } \\
\text { al } \\
\text { Data } \\
\text { Strat. } \\
\text { [67] }\end{array}$ & $\begin{array}{l}\text { IB } \\
\mathrm{M} \\
{[68]}\end{array}$ & $\begin{array}{l}\text { Break } \\
\text { throu } \\
\text { gh } \\
{[69]}\end{array}$ & $\begin{array}{l}\text { Equif } \\
\text { ax } \\
{[70]}\end{array}$ & $\begin{array}{l}\text { Big } \\
\text { Data } \\
\text { Fram } \\
\text { ewor } \\
\text { k } \\
{[71]}\end{array}$ \\
\hline \multirow{3}{*}{ Purpose } & $\begin{array}{l}\text { Strategy } \\
\text { Dev. }\end{array}$ & & & & $\bullet$ & & • & & • & & \\
\hline & $\begin{array}{l}\text { Business } \\
\text { Dev. }\end{array}$ & $\bullet$ & - & $\bullet$ & & $\bullet$ & & $\bullet$ & & & $\bullet$ \\
\hline & Product Dev. & & & & & & & & & - & \\
\hline \multirow{3}{*}{ Level } & Functional & $\bullet$ & & $\bullet$ & & & & & & $\bullet$ & \\
\hline & Business & & - & & & $\bullet$ & $\bullet$ & $\bullet$ & $\bullet$ & & $\bullet$ \\
\hline & Corporate & & & & $\bullet$ & & & & & & \\
\hline \multirow{3}{*}{ Practice } & Method & $\bullet$ & & & & $\bullet$ & & & & & $\bullet$ \\
\hline & Model & & & & $\bullet$ & & & - & & & \\
\hline & $\begin{array}{l}\text { General } \\
\text { Framework }\end{array}$ & & $\bullet$ & • & & & • & & • & • & \\
\hline \multirow{4}{*}{ Data Assets } & Master Data & & & & - & & - & & & & \\
\hline & $\begin{array}{l}\text { Customer } \\
\text { Data }\end{array}$ & & & $\bullet$ & & & & & • & • & \\
\hline & Process Data & - & & & & - & - & - & - & & \\
\hline & Big Data & & - & - & - & - & $\bullet$ & $\bullet$ & 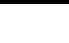 & & - \\
\hline \multirow{2}{*}{ Data Source } & Internal & & $\bullet$ & & $\bullet$ & $\bullet$ & & $\bullet$ & & & $\bullet$ \\
\hline & $\begin{array}{l}\text { Internal and } \\
\text { External }\end{array}$ & $\bullet$ & & $\bullet$ & & & $\bullet$ & & $\bullet$ & - & \\
\hline \multirow{3}{*}{$\begin{array}{l}\text { Strategic } \\
\text { Statement }\end{array}$} & Mission & - & $\bullet$ & & & & & & - & & \\
\hline & Vision & $\bullet$ & $\bullet$ & & $\bullet$ & & & & . & & \\
\hline & Objectives & - & - & & $\bullet$ & $\bullet$ & $\bullet$ & $\bullet$ & $\cdot$ & $\bullet$ & $\bullet$ \\
\hline \multirow{4}{*}{$\begin{array}{l}\text { Business IT } \\
\text { Alignment }\end{array}$} & Objectives & - & - & $\bullet$ & $\bullet$ & - & - & - & - & - & - \\
\hline & Architecture & - & & & $\bullet$ & $\bullet$ & $\bullet$ & & & & $\bullet$ \\
\hline & People & & - & - & & & & - & & & \\
\hline & $\begin{array}{l}\text { Communicat } \\
\text { ion }\end{array}$ & $\bullet$ & - & $\bullet$ & & & & & & & \\
\hline \multirow{3}{*}{$\begin{array}{l}\text { Strategy } \\
\text { Implementati } \\
\text { on }\end{array}$} & Road Map & - & $\bullet$ & $\bullet$ & & $\bullet$ & $\bullet$ & $\bullet$ & $\bullet$ & & $\bullet$ \\
\hline & Roles & & - & & $\bullet$ & & $\bullet$ & - & & & \\
\hline & $\begin{array}{l}\text { Resource } \\
\text { Allocation }\end{array}$ & $\bullet$ & & • & & • & $\bullet$ & & & - & - \\
\hline \multirow{4}{*}{$\begin{array}{l}\text { Service and } \\
\text { Support }\end{array}$} & $\begin{array}{l}\text { Use Case } \\
\text { Derivation }\end{array}$ & & & & $\bullet$ & $\bullet$ & & & • & - & \\
\hline & $\begin{array}{l}\text { Data } \\
\text { Management } \\
\text { Optimization }\end{array}$ & - & - & & - & - & - & - & - & & - \\
\hline & $\begin{array}{l}\text { Analytics } \\
\text { Improve. }\end{array}$ & $\bullet$ & & • & • & $\bullet$ & • & • & & & \\
\hline & $\begin{array}{l}\text { Strat. } \\
\text { Management } \\
\text { Improve. }\end{array}$ & - & & • & & $\bullet$ & • & $\bullet$ & • & • & - \\
\hline
\end{tabular}




\section{$5 \quad$ Discussion, Implications and Further Research}

Our research created a taxonomy for data strategy tools and methodologies using a structured literature review and the method by [18]. The design and application of the taxonomy answers the main research question of this research paper.

From our research, we can deviate several managerial and scientific implications. In terms of managerial implications, this taxonomy serves as a tool for organizations to create new or assess existing data strategy tools and methodologies in order to draw conclusions for their individual data strategy approach and derivation. Our findings emphasize the holistic range of the strategic approach on data as a data strategy can impact an organization from a functional to a corporate level. In that regard, a comprehensive understanding of data strategy, its tools and methodologies is a prerequisite to draw implications for a unique, organization-wide data strategy and our taxonomy supports such a comprehensive understanding. The implementation or concretization of a data strategy requires significant insights in order to incorporate a sustainable organization-wide conception of data-driven value generation, which is supported by our taxonomy, as it systematically disaggregates data strategy interpretations.

As for the scientific implications, our research created a resolute and profound analysis of data strategy tools and methodologies. Our analysis had both a deductive as well as an inductive approach to derive our results theoretically and verify them empirically in order to generate a common understanding of data strategy. Our aim was to improve the body of knowledge on data strategy tools and methodologies and to support future researches by systematizing and classifying different data strategy comprehensions. Our taxonomy serves as a tool to profoundly describe and distinguish data strategy tools from one another to emphasize the differences and commonalities. We hope to diminish the gap between the scientific field and economics as well between different researchers.

Naturally, our research has limitations. Since the derivation of a data strategy involves a variety of stakeholders [2] and creates specific use cases [24], it is an everevolving and unique endeavor. Therefore, our taxonomy requires critical updating and questioning in the shadow of technological, economical and societal changes in order to stay relevant and up to date. Furthermore, limitations arise from subjectivity, as other researchers might value or derive other dimensions and characterizations differently. With our research method, we tried to secure objectivity and impede bias as much as possible. Lastly, limitations arise from the fact that the scientific field of data strategy and its respective tools are relatively new and therefore subject to change and updates.

Future research in this field could incorporate the derivation of archetypical patterns, as it is a common instance in IS taxonomy research [72]. Besides, further research could include a structural analysis for data strategy and its tools for a specific area and perform a scientific comparison to derive sectoral differences of data strategy. 


\section{References}

1. Wong, T.Y.T., Peko, G., Sundaram, D., Piramuthu, S.: Mobile environments and innovation co-creation processes \& ecosystems. Information \& Management 53, 336-344 (2016)

2. Wilberg, J., Triep, I., Hollauer, C., Omer, M.: Big Data in Product Development: Need for a Data Strategy. In: Proceedings of PICMET '17 (2017)

3. Mintzberg, H.: The Strategy Concept I: Five Ps For Strategy. California Management Review (1987)

4. Sull, D., Turconi, S., Sull, C., Yoder, J.: Turning Strategy Into Results. MIT Sloan Management Review (2017)

5. Altamony, H., Alshurideh, M.T., Masa'deh, Ra'ed, Obeidat, B.: Information Systems for Competitive Advantage: Implementation of an Organisational Strategic Management Process. In: Innovation and Sustainable Competitive Advantage: From Regional Development to World Economies (2012)

6. Collis, D.J., Rukstad, M.G.: Can You Say What Your Strategy Is? Harvard Bus. Rev. (2008)

7. Otto, B., Österle, H.: Corporate Data Quality. Springer Berlin Heidelberg, Berlin, Heidelberg (2016)

8. Lim, C., Kim, K.-H., Kim, M.-J., Heo, J.-Y., Kim, K.-J., Maglio, P.P.: From data to value: A nine-factor framework for data-based value creation in informationintensive services. International Journal of Information Management 39, 121-135 (2018)

9. Mazzei, M.J., Noble, D.: Big data dreams: A framework for corporate strategy. Business Horizons 60, 405-414 (2017)

10. Ebner, K., Buhnen, T., Urbach, N.: Think Big with Big Data: Identifying Suitable Big Data Strategies in Corporate Environments. In: 2014 47th Hawaii International Conference on System Sciences, pp. 3748-3757. IEEE (2014)

11. Hurley, J.: WHY YOUR DATA STRATEGY IS YOUR B2B GROWTH STRATEGY. Harvard Bus. Rev. (2018)

12. Wilberg, J., Kalla, T., Fetscher, M., Rimböck, F., Hollauer, C., Omer, M.: Managing technological entrepreneurship: the engine for economic growth. PICMET'18 : Portland International Conference on Management of Engineering and Technology. In: PICMET (2018)

13. Posavec, A.B., Krajnovic, S.: Challenges in adopting big data strategies and plans in organizations. In: 2016 39th International Convention on Information and Communication Technology, Electronics and Microelectronics (MIPRO), pp. 1229-1234. IEEE (2016)

14. SAS: 5-essential-components-of-data-strategy- (2019)

15. Barton, D., Court, D.: Three keys to building a data driven strategy. Mckinsey\&Company Quarterly (2013)

16. Gurevich, A., Dey, S.: Defining a data strategy (2018)

17. Etsiwah, B., Hilbig, R.: What is Data Strategy? An Analysis of an ambiguous Concept. In: ISPIM Innovation Conference. Florence (2019) 
18. Nickerson, R.C., Varshney, U., Muntermann, J.: A method for taxonomy development and its application in information systems. European Journal of Information Systems 22, 336-359 (2013)

19. Azkan, C., Iggena, L., Gür, I., Möller, F., Otto, B.: A Taxonomy for Data Driven Services in Manufacturing Industries. In: Twenty-Fourth Pacific Asia Conference on Information Systems,. Dubai (2020)

20. Valdez, A., Cortes, G., Castaneda, S., Vazquez, L., Zarate, A., Salas, Y., Haces, G.: Big Data Strategy. IJACSA 10 (2019)

21. Lakoju, M., Serrano, A.: Saving Costs with a Big Data Strategy Framework. In: IEEE International Conference on Big Data (BIGDATA) (2017)

22. DalleMulle, L., Davenport, T.: What's Your Data Strategy - DalleMule. Harvard Bus. Rev. (2017)

23. Hochhauser, R.: Data strategy: a critical component of marketing success. Handbook of Business Strategy 5, 227-232 (2004)

24. Lakoju, M., Serrano, A.: Framework for Aligning Big-Data Strategy with Organizational Goals. In: Twenty-third Americas Conference on Information Systems. Boston (2017)

25. Davenport, T.: Big Data at Work. Dispelling the Myths, Uncovering the Opportunities. Harvard Business Review Press, Boston (2014)

26. Chanias, S., Myers, M.D., Hess, T.: Digital transformation strategy making in pre-digital organizations: The case of a financial services provider. The Journal of Strategic Information Systems 28, 17-33 (2019)

27. Bharadway, A., El Sawy, O.A., Pavlou, P.A., Venkatraman, N.: Digital Business Strategy: Toward a next generation of Insights. Mis Quart. (2013)

28. Ross, J.W., Beath, C., Moloney, K.G., Sebastian, I.M., Mocker, M., Fonstad, N.O.: Designing and Executing Digital Strategies. In: ICIS. Dublin (2016)

29. Sebastian, I.M., Ross, J.W., Beath, C., Mocker, M., Moloney, K.G., Fonstad, N.O.: How Big Old Companies Navigate Digital Transformation. Mis Quart. (2017)

30. Gurbaxani, V., Dunkle, D.: Gearing Up For Successful Digital Transformation. MISQE 18, 209-220 (2019)

31. Porter, M.E., Heppelmann, J.E.: How Smart, Connected Products Are Transforming Competition. Harvard Business Review 92, 64-88 (2014)

32. Porter, M., Heppelmann, J.: How Smart, Connected Products Are Transforming Companies. Harvard Business Review (2015)

33. Yeow, A., Soh, C., Hansen, R.: Aligning with new digital strategy: A dynamic capabilities approach. The Journal of Strategic Information Systems 27, 43-58 (2018)

34. Henderson, J.C., Venkatraman, N.: Strategic alignment: Leveraging information technology for transforming organizations. IBM Syst. J. (1999)

35. Bartenschlager, J., Goeken, M.: Designing Artifacts of IT Strategy for Achieving Business/IT Alignment. In: Americas Conference on Information Systems (2009)

36. Chen, D., Mocker, M., Preston, D., Teubner, A.: Information Systems Strategy: Reconceptualization and Implications. In: MISQ 2010, pp. 233-259 (2010) 
37. Mithas, S., Rust, R.T.: HOW INFORMATION TECHNOLOGY STRATEGY AND INVESTMENTS INFLUENCE FIRM PERFORMANCE- CONJECTURE AND EMPIRICAL EVIDENCE. Mis Quart. (2016)

38. Holotiuk, F., Beimborn, D.: Critical Success Factors of Digital Business Strategy. In: 13th International Conference on Wirtschaftsinformatik, (2017)

39. Drechsler, A., Weißschädel, S.: An IT strategy development framework for small and medium enterprises. Inf Syst E-Bus Manage 16, 93-124 (2018)

40. Cuenca, L., Boza, A., Ortiz, A., Trienekens, J.J.M.: Business-IT Alignment and Service Oriented Architecture - A Proposal of a Service-Oriented Strategic Alignment Model. In: Proceedings of the 16th International Conference on Enterprise Information Systems, pp. 490-495. SCITEPRESS - Science and and Technology Publications (2014)

41. Ball, N., Adams, C., Xu, W.: Overcoming the Elusive Problem of IS/IT Alignment: Conceptual and Methodological Considerations. In: Americas Conference on Information Systems (2003)

42. Möller, F., Stachon, M., Hoffmann, C., Bauhaus, H., Otto, B.: Data-Driven Business Models in Logistics: A Taxonomy of Optimization and Visibility Services. In: Proceedings of the 53rd Hawaii International Conference on System Sciences, pp. 5379-5388 (2020)

43. Paukstadt, U., Strobel, G., Eicker, S.: Understanding Services in the Era of the Internet of Things: A Smart Service Taxonomy. In: ECIS 2019 (2019)

44. Hunke, F., Engel, C., Schüritz, R., Ebel, P.: Understanding the anatomy of analytics-based services - A taxonomy to conceptualize the use of data and analytics in services. In: ECIS 2019 (2019)

45. Hartmann, P.M., Zaki, M., Feldmann, N., Neely, A.: Capturing value from big data - a taxonomy of data-driven business models used by start-up firms. IJPEM 36, 1382-1406 (2016)

46. Hevner, A.R., March, S.T., Park, J., Ram, S.: Design Science in Information Systems Research. Mis Quart. 28, 75-105 (2004)

47. King, W.R., He, J.: Understanding the Role and Methods of Meta-Analysis in IS Research. CAIS 16 (2005)

48. Paré, G., Trudel, M.-C., Jaana, M., Kitsiou, S.: Synthesizing information systems knowledge: A typology of literature reviews. Information \& Management 52, 183-199 (2015)

49. Vom Brocke, J., Simons, A., Niehaves, B., Reimer, K., Plattfaut, R., Cleven, A.: Reconstructing the Giant: On the Importance of Rigour in Documenting the Literature Search Process. In: Proceedings of the 17th European Conference on Information Systems. AIS, Verona, Italy (2009)

50. Fink, A.: Conducting research literature reviews. From the internet to paper. SAGE, Los Angeles, London, New Delhi, Singapore, Washington DC (2014)

51. Levy, Y., Ellis, T.J.: A Systems Approach to Conduct an Effective Literature Review in Support of Information Systems Research. Informing Science: The International Journal of an Emerging Transdiscipline 9, 181-212 (2006)

52. Webster, J., Watson, R.T.: Analyzing the Past to Prepare for the Future: Writing a Literature Review. Mis Quart. 26, xiii-xxiii (2002) 
53. Vom Brocke, J., Simons, A., Riemer, K., Niehaves, B., Plattfaut, R., Cleven, A.: Standing on the Shoulders of Giants: Challenges and Recommendations of Literature Search in Information Systems Research. CAIS 37, 205-224 (2015)

54. Lakoju, M., Serrano, A.: A strategic approach for visualizing the value of big data (SAVV-BIGD) framework. In: 2016 IEEE International Conference on Big Data (Big Data), pp. 1334-1339. IEEE (2016)

55. Vayghan, J., Garfinkle, S., Walenta, C., Healy, D., Valentin, Z.: The internal information transformation of IBM. IBm Systems Journal, 669-683 (2007)

56. Cuenca, L., Boza, A., Ortiz, A.: An enterprise engineering approach for the alignment of business and information technology strategy. International Journal of Computer Integrated Manufacturing 24, 974-992 (2011)

57. Otto, B.: Quality and Value of the Data Resource in Large Enterprises. Information Systems Management 32, 234-251 (2015)

58. Bakhtiani, R., Gandhi, M., Churi, P., Gupta, P.: Big Data Strategies - A Review and Survey. In: 4th International Conference on Applied and Theoretical Computing and Communication Technology iCATccT (2018)

59. Falge, C.: Methode zur Strategieentwicklung für unternehmensweites Datenqualitätsmanagement in globalen Konzernen. St.Gallen (2015)

60. Wilberg, J., Fetscher, M., Rimböck, F., Hollauer, C., Omer, M.: Development of a Use Phase Data Strategy for Connected Products: A Case Study in Industry. In: Proceedings of PICMET '18 (2018)

61. Adner, R.: Match Your Innovation Strategy to Your Innovation Ecosystem. Harvard Bus. Rev. 84, 98-107; 148 (2006)

62. Booz Allen Hamilton: Booz Allen Hamilton Data Strategy Framework, https://www.boozallen.com/s/insight/thought-leadership/a-framework-to-guideyour-data-strategy.html

63. CDQ: Data Strategy Canvas, https://www.cc-cdq.ch/request-publications\#16

64. Measurelab: Measurelab Data Strategy Canvas, https://www.measurelab.co.uk/blog/what-is-a-data-strategy-and-do-i-need-one/

65. Boston Consulting Group: BCG Data Strategy Transformation Model, https://www.bcg.com/publications/2017/digital-transformation-transformationdata-driven-transformation

66. Keller Schroeder: Data Strategy Framework, https://www.kellerschroeder.com/data-strategy-framework/

67. Global Data Strategy: Data Strategy Framework, https://globaldatastrategy.com/our-services/data-strategy/

68. IBM: IBM Big Data Maturity Model, https://www.ibmbigdatahub.com/blog/bigdata-analytics-maturity-model

69. Breakthrough Strategy: Breakthrough Data Strategy Canvas (2019)

70. Equifax: Data Strategy Framework, https://www.dataversity.net/developing-andexecuting-a-global-data-strategy/

71. Big Data Framework: Big Data Strategy Framework, https://www.bigdataframework.org/formulating-a-big-data-strategy/

72. Glass, R.L., Vessey, I.: Contemporary Application-Domain Taxonomies. IEEE Softw. 12, 63-76 (1995) 